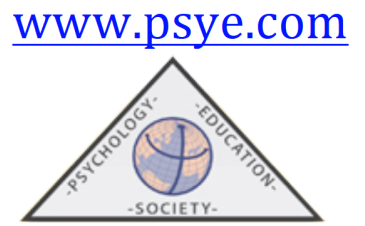

\title{
Geometry teaching experience in virtual reality with NeoTrie VR
}

\author{
Diego CANGAS ${ }^{1}$, Grażyna MORGA² \& José L. RODRÍGUEZ ${ }^{3}$ \\ ${ }^{1,3}$ University of Almería, Spain \\ ${ }^{2}$ Zespół Szkolno-Przedszkolny w Żernicy, Poland
}

(Received on January 21, 2019; Accepted on May 15, 2019)

\begin{abstract}
The possibilities of using the new software of virtual reality NeoTrie VR (or Neotrie) to teach geometry to children aged 11-14 years old are presented. This software is tested for the first time as a part of math lessons at a School in Żernica (Poland). The use of Neotrie has made it easier to eliminate some of the problems faced by the pupils in the early stages of geometry learning. Moreover, the participating students solve geometric tasks more quickly, compared with previous years, especially those that require spatial imagination and those with a higher degree of difficulty. Since the program has been implemented, pupils are more active and prone to cooperation, and to formulate conclusions. Neotrie turns out to be a useful tool for teaching Geometry, it helps students to better organize their geometric knowledge in a ludic way, to increase their spatial reasoning and creativity.
\end{abstract}

Keywords: Education, motivation, innovation, virtual reality, geometry, mathematics.

\section{Experiencia de enseñanza de la Geometría con NeoTrie VR}

RESUMEN: Se presentan las posibilidades que ofrece el nuevo software NeoTrie VR (o Neotrie) en la enseñanza de la Geometría, a partir de la experiencia llevada a cabo con alumnado de 11 a 14 años de edad, en un centro de Enseñanza Primaria en Żernica (Polonia). El uso de Neotrie ha facilitado que los participantes superen algunos de los obstáculos con los que normalmente se encuentran en el aprendizaje de la Geometría. Además, los estudiantes participantes resuelven problemas geométricos con más rapidez, en relación a otros cursos anteriores, especialmente aquellos problemas que requieren una mayor visión espacial y entrañan mayor grado de dificultad. Desde que se utiliza dicho programa, el alumnado está más activo y abierto a cooperar, a participar en la formulación de conclusiones. Neotrie resulta ser una herramienta útil para enseñar Geometría, ayuda a que el alumnado organice mejor sus conocimientos de Geometría de forma lúdica, a que mejore su razonamiento espacial y potencie su creatividad.

Palabras clave: Educación, motivación, creatividad, innovación, realidad virtual, geometría, razonamiento espacial, matemáticas.

Correspondencia: José L. Rodríguez, Departamento de Matemáticas, CITE III, Universidad de Almería, 04120 La Cañada de San Urbano, Almería, Spain. E-mail: jlrodri@ual.es 


\section{Introduction}

Although mathematics is referred to as the 'queen of science', many pupils and adults consider it a difficult and boring subject. Most students quickly become discouraged and feel that they do not understand it or they cannot learn it. Geometry, which children learn from a very young age, poses particular difficulties. This is largely due to children's problems with spatial imagination.

Spatial reasoning is a basic skill in geometry, and the link between early spatial reasoning and later mathematical developments has been recorded in the literature (e.g. Guay and McDaniel 1977; Battista 2007; Bruce and Hawes 2015; Dindyal 2015). It is an essential part of everyday life, crucial in science and many other fields of knowledge. According to Hoffer (1981), there are five important skills that should be developed during teaching of geometry:

1. visual skills (recognition, observation);

2. verbal skills (correct use of terminology and accurate communication in the description of spatial concepts and relations);

3. drawing skills (communication through drawing, ability to present geometric shapes in 2D and 3D, making scale graphs, sketching isometric drawings);

4. logical skills (classification, recognition of basic properties as criteria, distinguishing patterns, formulating and testing hypotheses, drawing conclusions, using opposite examples); and

5. practical skills.

However, Moss et al. (2015) reports that teaching geometry is often limited to naming shapes, counting sides and walls and dealing primarily with static 2D and 3D shapes. Also, Wai et al. (2009) concluded that spatial skills have rarely been included in mathematics curricula, so existing curricula need to be modified. The American National Research Council (2006) considers spatial thinking as a basic skill that can be learned and formally taught to all students using well-designed tools, technologies and curricula. Therefore, geometry and spatial reasoning should be part of any curriculum in early childhood.

The National Council for Teachers of Mathematics in the United States recommended in 2008 that at least half of early mathematics curricula should focus on geometry, measurement and spatial reasoning, but that the resources used for this purpose are insufficient (Clements and Sarama 2004, 2011; Ehrlich et al. 2006; Dindyal 2015).

According to Dindyal (2015), schools need to establish the necessary links to the real world of content that children learn from geometry lessons. In addition, learning of geometry should be pleasant for children. The child should work in cooperation with other children and the teacher, and teaching should, therefore, cover a wide range of approaches, including play. The need to introduce young children to tasks that relate to a more dynamic and transformational approach 
to geometry and spatial sense was also noticed. It is proposed that geometry should be introduced as a dynamic, spatial and inventive concept for children in their early years (Moss et al. 2015) rather than approaching geometry as a topic mainly concerned with labelling and shape classification. Issues relating to curricula, learning, teaching and evaluation in early school years also need to be carefully considered (Dindyal 2015), especially since children are able to exceed current programme expectations if they have adequate opportunities to learn (Moss et al. 2015).

It is also important to change the attitude of students towards learning geometry, which frequently is not positive. This can be done, for example, by using teaching methods based on information technology and computer programs. The advent of technology gives teachers an excellent opportunity to present geometry in a more dynamic way than ever before. Clements et al. (1993) noted very accurately that technology is extremely important in teaching young people, and that, used judiciously, it supports the educational environment and enables children to flourish. Moreover, children are currently exposed to a wide range of technological devices, such as iPads, smartphones, computers and many types of electronic games and other software that are intended for both entertainment and information purposes (Dindyal, 2015). Therefore, the use of technology in teaching young children may increase educational effects. Several tools as sketchpads, iPads, interactive whiteboards, programmable robots as well as computer programs, were successfully used for this aim (Ng and Sinclair 2015; Kotsopolous et al. 2015; Kaur 2015; Bartolini-Bussi and Baccaglini-Frank 2015; Soury-Lavergne and Maschietto 2015).

The structure of the article is as follows: First, we describe the most important features and properties of the software we have developed to carry out this pilot experience. Next, we describe the group of participants involved and the procedure we have followed, taking into account the novelty and characteristics of the software. Finally, we describe the results obtained, as well as the scope and areas in which we believe the software may be applied in the future.

\section{Characteristics and properties of NeoTrie VR}

NeoTrie VR (shortly "Neotrie") is a new software package of virtual reality which is currently being developed by Virtual Dor (a spin-off of the University of Almería), which enables pupils to create, manipulate and interact with 3D geometrical objects and 3D models of several types; see (Cangas, Crespo, Rodríguez, Zarauz, 2019) for a survey of the first version.

The chosen VR system for this testing period (March to June 2018) was the HTC Vive (which consists of a headset, two base stations, and two controllers). The computer we used has a processor i7-6700/32GB, graphic card NVIDIA GeForce ${ }^{\mathrm{TM}}$ GTX 1070, and OS Windows 10 (less requirements are valid too, see the website of HTC Vive for details).

During the testing period, we changed the old scenario (a single floor and a sky) to a neoclassic temple, where the player can walk and teleport around the temple, and meet a 3D animated character of Euclid. 


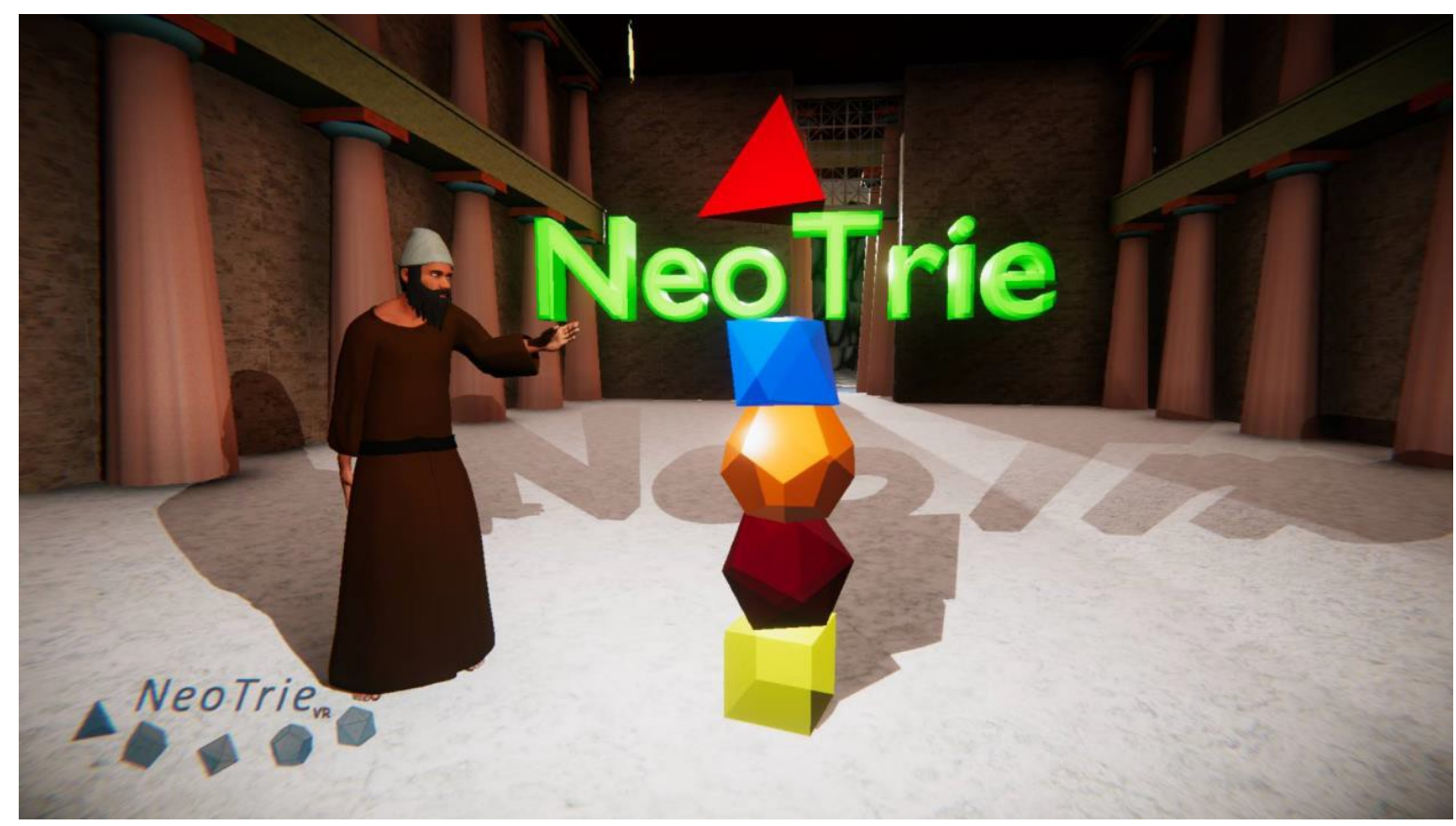

Figure 1. Euclid showing the five platonic solids

In the new version of Neotrie, the player can change the basic modes by passing its virtual hand over the symbols as shown in Figure 2: "plus" mode to create vertices and edges, "triangle" mode to create faces, "edit" mode to edit the position of vertices, "delete" to erase single elements of a figure, and "free pencil" to make annotations or drawings on space, and "object" mode to translate a figure.

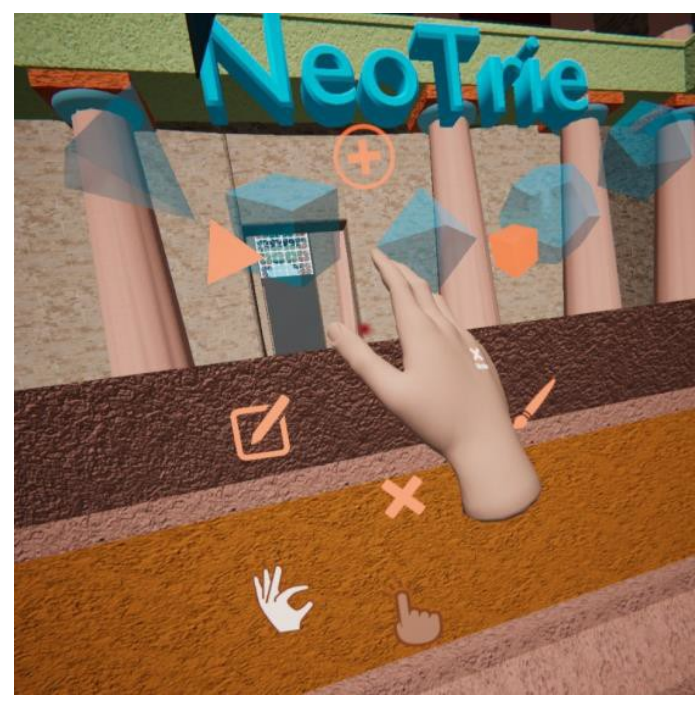

Figure 2. Basic modes

Some editing and geometric tools were included to meet the needs of the lessons to be tested (Figure 3): a brush and a palette of colours, a copy seal, an eraser, a rotation tool, a middle point tool, a protractor, a metric tape, among others, allowing pupils to paint, rotate the 
figures, and even get inside the figures, by enlarging them. Furthermore, the use of these tools was programmed to be intuitive, and as natural as possible (Figure 4).

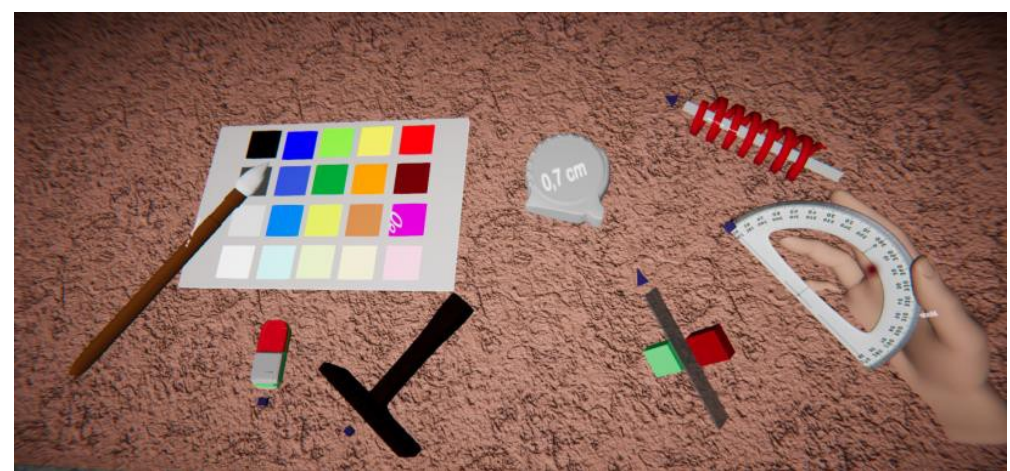

Figure 3. Some editing and geometric tools implemented in this testing period.

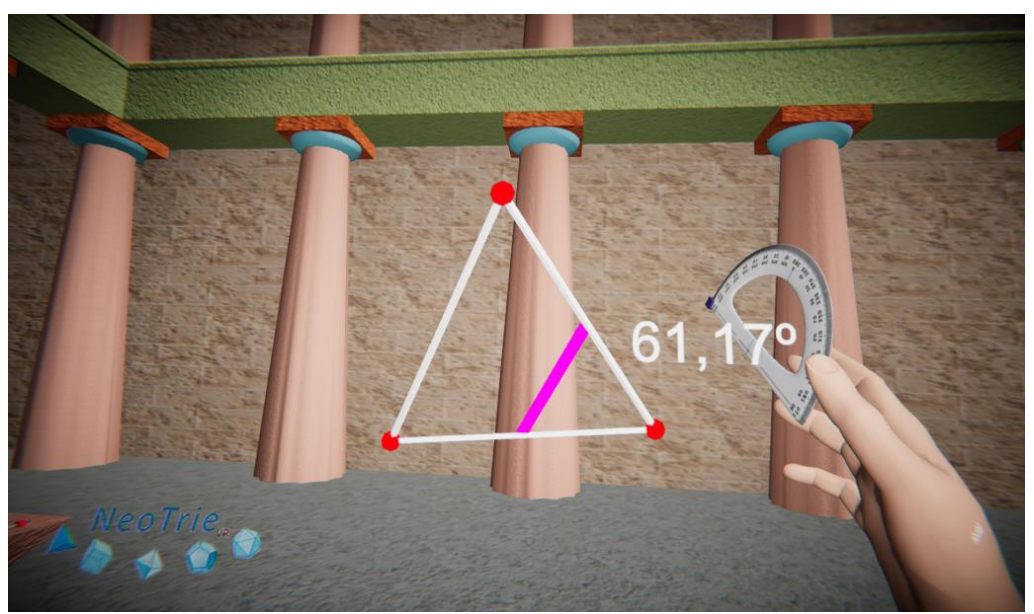

Figure 4. Measuring an angle of a triangle, which changes in real time when moving the vertices.

The Speech Recognition System to insert figures in the scene has been expanded to more than 100 predesigned geometric models. On any figure, it can be shown the number of vertices, edges, faces, and also its length, area, and volume, which allow pupils to check their exercises. Another new feature is sticking two figures. This allows pupils to make bigger and more complex constructions.

We also implemented a virtual camera to take pictures from the scene, with good framing and high resolution (all images in this article were taken with this virtual camera). We highlight the new online Multiplayer mode (Figures 5 and 6), still under development, which was first tested by the authors of this article and other collaborators. 

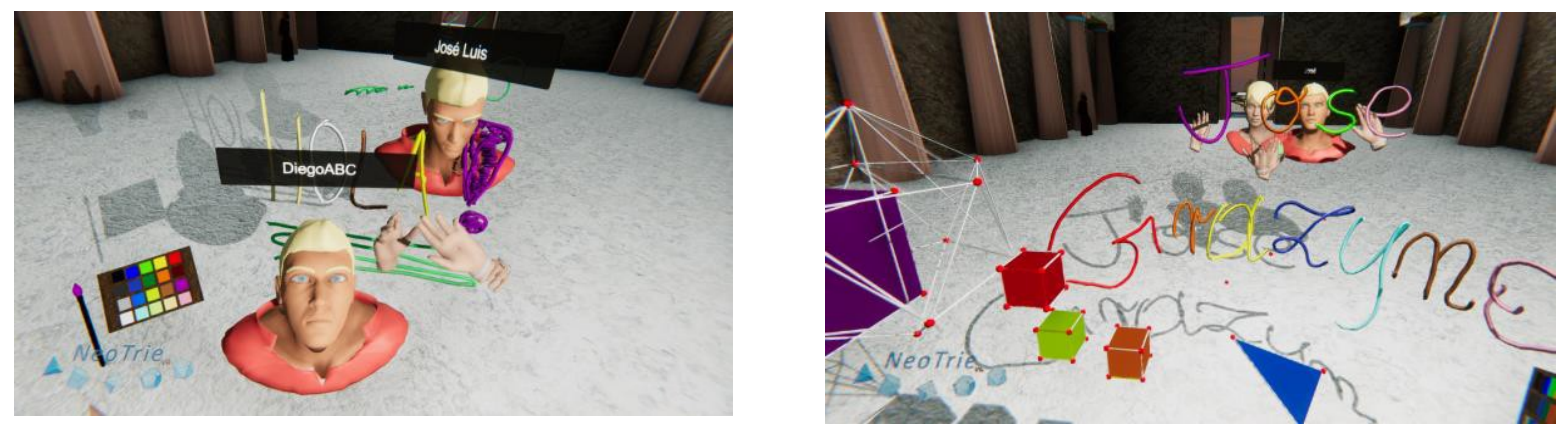

Figures 5 and 6. The authors playing in multiplayer mode inside a scene of Neotrie

We invite the reader to see our videos showing how all these tools and functions work https://www.youtube.com/channel/UCdLPDDusXOjAa16odHRkTsw/.

\section{Participants}

Neotrie is tested as a part of math lessons at the public school in Żernica (Poland). The purpose of these tests is to analyze possible didactic applications of the program and formulate opinions and feedback for its further improvement.

The classes have been conducted from March to June, 2018, in three classes of children from three age groups, namely: 11, 12 and 14 years old. The number of pupils in each class was 18-26. In total, 25 lessons were carried out, based on the core curriculum in math, in Poland. The topics referring to angles, polygons, prisms and pyramids were implemented, according to this curriculum. In most of the classes the software was used during the whole lesson, sometimes only in a part of it, depending on the needs. Additional classes were also organized within the scheme of the "scientific circle" (voluntary classes for the best students, who are especially interested in math and who are able to solve more complicated mathematical problems).

The class in which the lessons were conducted is equipped with a large monitor (55"), enabling the teacher and all other pupils to control the activities done with the computer program.
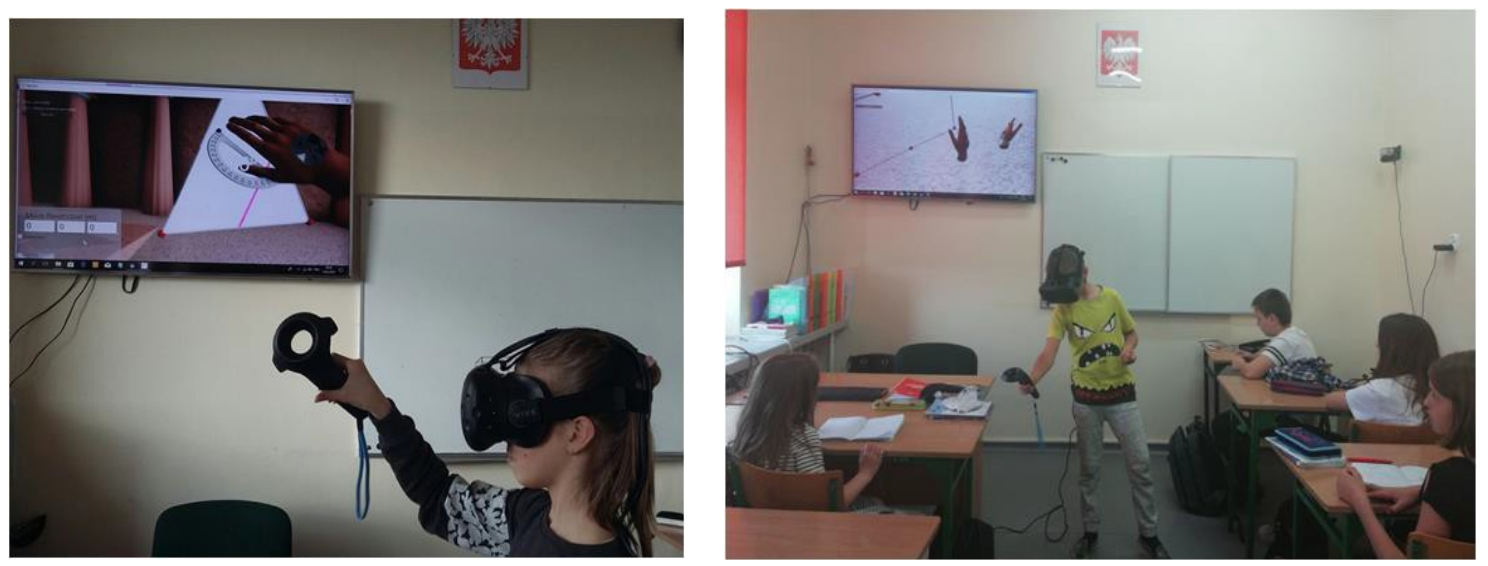

Figures 7 and 8. Pictures at the classroom 


\section{Procedure}

During the first lessons with the use of Neotrie, pupils learned about the basic functions of the program and the use of controllers. Additional classes were also organised for children who had problems with mastering its basic functions.

At the beginning of each lesson, pupils were assigned to carry out tasks using the program. The number of pupils varied between 3 and 5. Thanks to the use of the monitor, the rest of the pupils were able to follow and actively participate in the task by giving suggestions. On some of the classes, the children worked in groups and they had to develop their own strategy to do the task, using adequate tools. They also chose one delegate who performed the task. Competition between groups influenced cooperation between children in each group. Therefore, pupils felt responsible for the results of the group, they were focused and involved. This allowed all children to participate in the lesson. Some lessons with the use of Neotrie were only taught by the teacher. Sometimes the teacher did not use the board, but wrote down all the important information using the program. During the classes, the teacher also introduced simple mathematical vocabulary in English.

The lesson scenarios were prepared for each age group. They contained the most important information on flat or spatial figures being the subject of a lesson, namely: definitions, characteristics and classifications. They also included a list of tasks to be done, using Neotrie to assimilate and repeat the acquired knowledge. These tasks, depending on the subject, comprised: drawing flat figures (immersed on space); indicating their sides, vertices, angles and diagonals; measuring lengths of sides, measuring angles, constructing triangles, constructing prisms or pyramids on a given basis; as well as indicating and painting their faces, edges and vertices. Pupils built polygons with different areas, as well as prisms of a given volume. They measured segments of solids and they could enlarge and rotate solids. Finally, they could take photos of all their figures with the virtual camera. Below we can see photos of some of the activities (Figures 9-14):

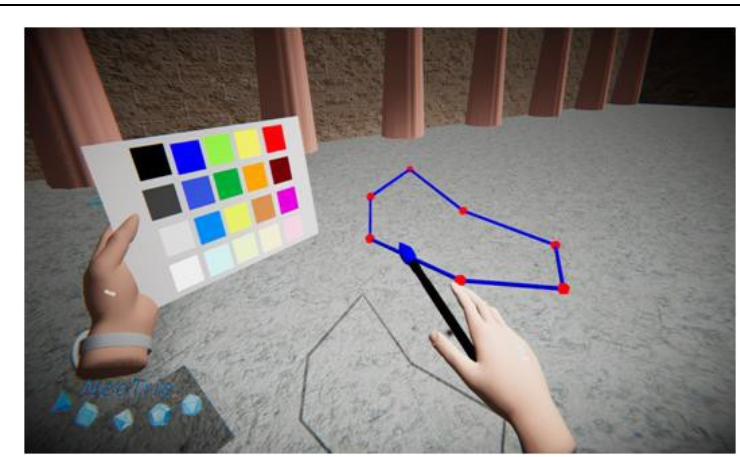

Figure 9. Drawing polygons, indicating their sides, vertices and angles

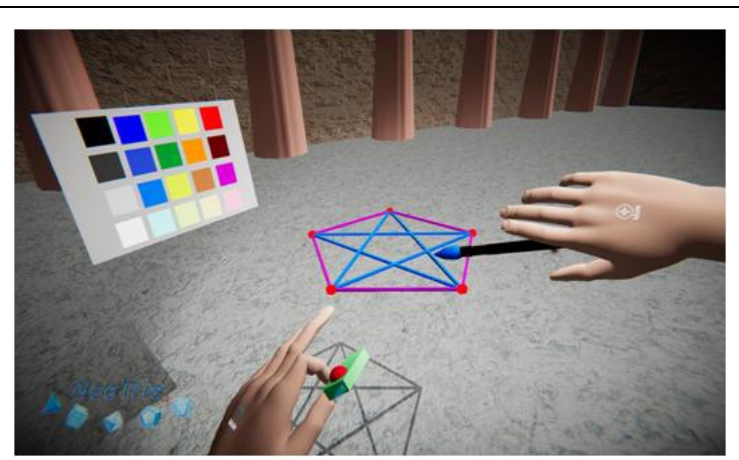

Figure 10. Drawing diagonals of a pentagon 


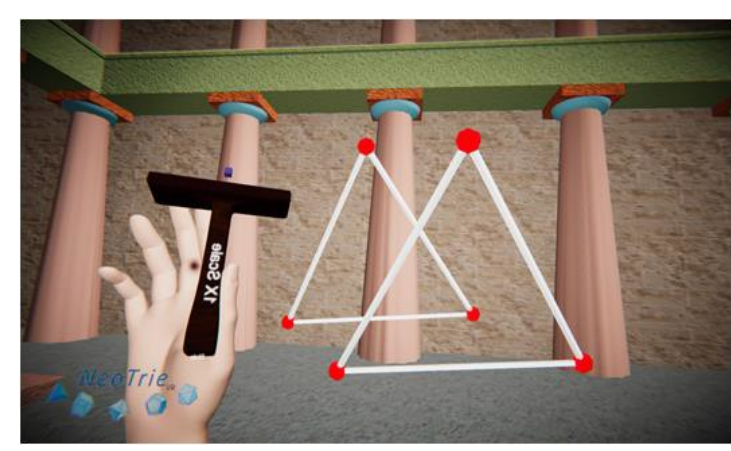

Figure 11. The seal tool allows to copy the base to make a prism

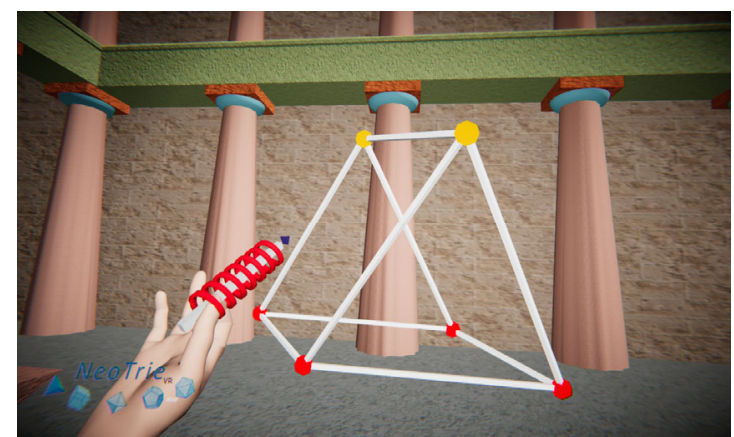

Figure 13. This tool allows to rotate a figure, by fixing two points of the rotating axis

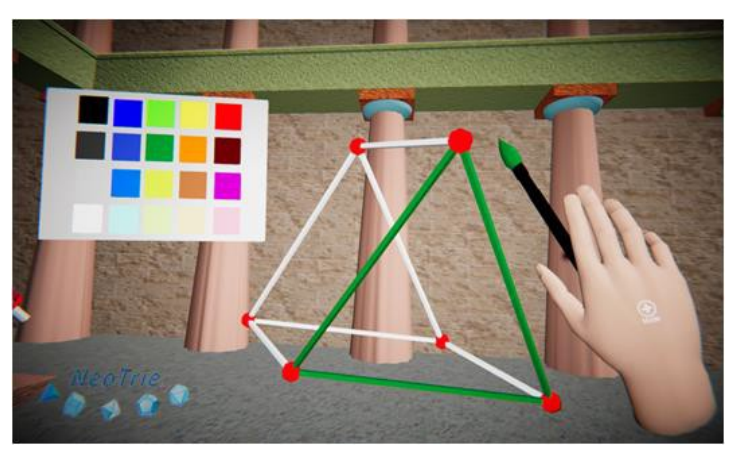

Figure 12. One can paint the edges with the brush

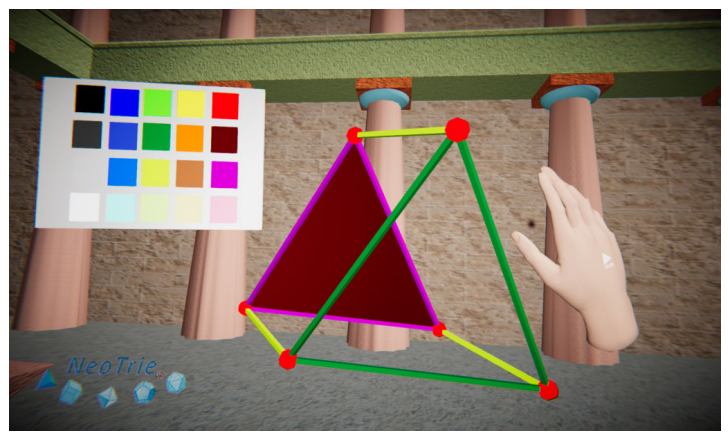

Figure 14. Filling the faces of the prism by the "triangle" mode

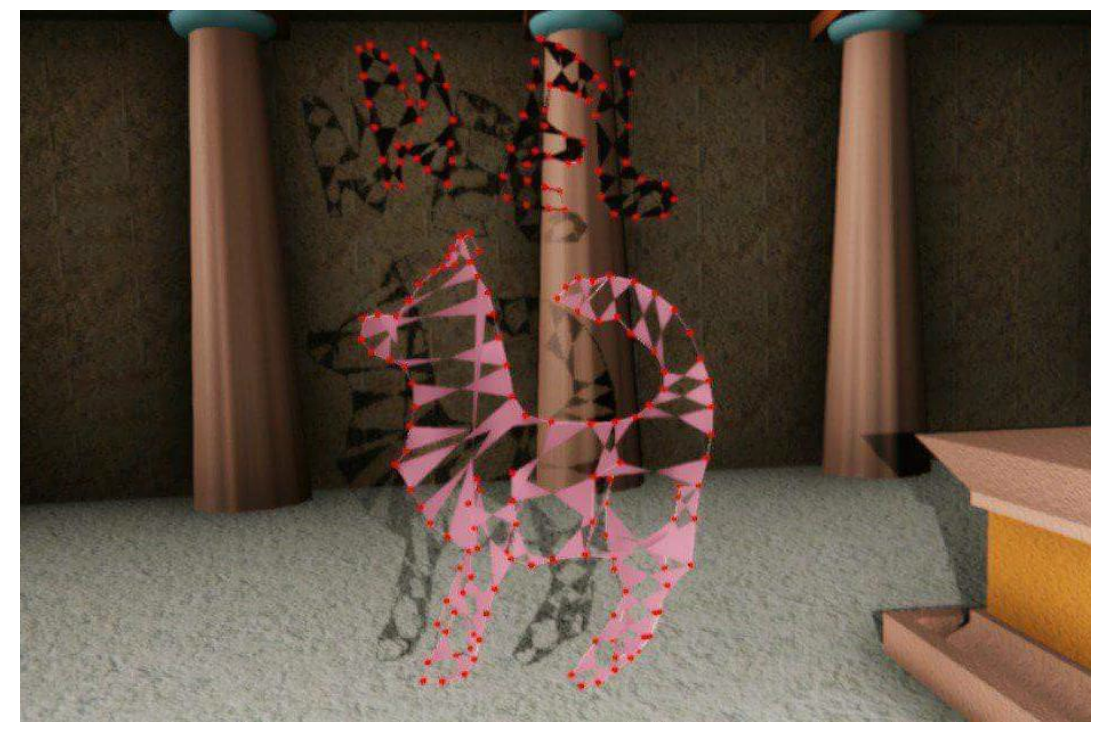

Figure 15. Creature made by one of the pupils during free time 


\section{Results}

The use of Neotrie has made it easier to eliminate some of the problems faced by the pupils in the early stages of the Geometry learning. Children very often have trouble with understanding the concept of area of a figure, and they confuse the area with the perimeter and vice versa. Thanks to Neotrie, they could see the relationship between the sides of a rectangle and its area and perimeter. They could also understand the difference between its area and perimeter. Having found out that the squares that fill a rectangle are congruent, children were able to provide themselves with a way to calculate the area of a rectangle or a square, and apply these concepts in practice. Similarly, they built cuboids and cubes filled with identical unit cubes and learned to define and calculate volume and to distinguish between surface area and volume. By using the program, the students noticed a correlation between the volume of the prism and the area of the base surface and height, which led them to induce a formula. They made necessary measurements of the prepared prism models and then calculated their volume.

Moreover, using the copying seal tool found out to be a very suitable way to learn the difference between similar and congruent figures, and also in constructing and studying the mathematical structure of tessellations. Thus, pupils learned how to build simple tessellations like the honeycomb with hexagons, and also some basic fractals like the Sierpinski triangle or the Sierpinski carpet.

They also understood the concept of solids' rotation when they rotated a triangle and a rectangle or a square around their own axis, to get a cone or a cylinder, respectively.

The effect of using the program is that now the participating students solve geometric tasks faster, compared with other methodologies, especially those tasks that require spatial imagination and those with a higher degree of difficulty. Since the program has been implemented, pupils are more active and prone to cooperation, and to formulate conclusions.

Especially younger children, but also older, weaker ones and those with some dysfunctions more easily overcome their shyness. It is a very important aspect, as stimulating positive feelings and beliefs of students in their own competence in math may lead to better math achievement (Timmerman et al. 2017). Colourful image and sound raise the attractiveness of classes, and thus increase the level of assimilation of new knowledge by pupils, making the lessons more effective.

\section{Conclusions and final comments}

The program is designed for teaching geometry at different stages of education, combining didactic values and fun. Taking into account the experience gained during the classes in which Neotrie was used, a few conclusions can be drawn:

- Neotrie appears to be a useful tool for teaching either 2D and 3D geometry, helping children to organize their geometric knowledge, expand their spatial imagination, and increase their creativeness (see Figures 1-15). 
- It is advised to organize an initial lesson for children explaining the basic tools and functions of Neotrie at the very beginning. It will help children to understand how to use Neotrie, and it will also increase their manual skills. This is especially needed for younger children (11-12 years old). Organization of additional classes for the pupils where they can practice using the controllers and repeat the tasks is also recommended.

- A method should be developed for evaluating the impact of Neotrie on the improvement of spatial imagination and geometric skills, and to obtain validated didactic sequences.

Thanks to our first pilot experience, which has involved the exchange of ideas and important improvements in the software, many other schools around the world are interested in using Neotrie in their math lessons. Indeed, several European educational centers of distinct levels have joined us as partners of the Neotrie project in the known Scientix platform. Different aspects of using the software in the educational practice, included the present ones, were discussed during the 1st International Meeting of NeoTrie VR in Almeria, on October 1st-2nd 2018.

We are currently studying the impact of using Neotrie, in collaboration with the research group of didactics of Mathematics of the University of Almería. On the other hand, we are collaborating with two associations of people with intellectual disabilities "A Toda Vela" from Almería, and "Civitas" from Gran Canarias, to validate the use of Neotrie for acquiring knowledge of the body schema, as well as improving the cognitive functions of attention, memory and visuospatial functions. We think that this study will be useful also for early ages in Geometry learning.

Neotrie, as a software package, is rapidly evolving with new functions and improvements, usable not only for mathematics, but other STEAM areas. Its use is being extended to a world global community, which every day sees more and more the didactic possibilities of using virtual reality in the classrooms and other social environments.

One of the main features not yet exploited in Neotrie is the multiplayer mode. This certainly will allow students (and also teachers) even from different countries to play and learn together in the same scene. This feature will help to strengthen relationships around the world, as well as to facilitate execution of many collaborative projects.

\section{Acknowledgments}

We would like to thank the reviewers and Isabel $\mathrm{M}^{\mathrm{a}}$ Romero, for the improvement proposals in the presentation of this article. The third was partially supported by FEDER-MEC grant MTM2016-76453-C2-2-P and the University of Almería. 


\section{References}

Bartolini-Bussi, M., \& Baccaglini-Frank, A. (2015). Geometry in early years: sowing seeds for a mathematical definition of squares and rectangles. ZDM Mathematics Education, 47(3), $391-405$.

Battista, M. T. (2007). The development of geometric and spatial thinking. In: F. Lester (Ed.), Second handbook of research on mathematics teaching and learning (pp. 843-908). Reston. National Council of Teachers of Mathematics.

Bruce, C., \& Hawes, Z. (2015). The role of 2D and 3D mental rotations in mathematics for young children: What is it? Why does it matter? And what can we do about it? ZDM Mathematics Education, 47(3), 331-343.

Cangas, D., Crespo, D., Rodríguez, J.L, \& Zarauz, A. (2019). NeoTrie VR: nueva geometría en realidad virtual, Pi-InnovaMath, Num. 2, 1-8.

Clements, D.H., Natasi, B.K., \& Swaminathan, S. (1993). Young children and computers: crossroads and directions from research. Young Children 1, 56-64.

Clements, D., \& Sarama, J. (2004). Engaging Young children in mathematics: standards for early childhood mathematics education. Mahwah: Erlbaum.

Clements, D. H., \& Sarama, J. (2011). Early childhood teacher education: the case of geometry. Journal of Mathematics Teacher Education, 14(2), 133-148.

Dindyal J. (2015). Geometry in the early years: a commentary. ZDM Mathematics Education 47 (3), 519-529.

Erhlich, S. B., Levine, S., \& Goldin-Meadow, S. (2006). The importance of gesture in children's spatial reasoning. Developmental Psychology, 42(6), 1259-1268.

Guay, R. B., \& McDaniel, E. D. (1977). The relationship between mathematics achievement and spatial abilities among elementary school children. Journal for Research in Mathematics Education, 8(3), 211-215.

Hoffer, A. (1981). Geometry is more than proof. Mathematics Teacher, 74, 11-18.

Jiménez, D., Rodríguez, J.L., (2014). Geometría flexible con Polifieltros 3D, Actas del XIV Congreso de Enseñanza y Aprendizaje de las Matemáticas, Diversiad y Matemáticas, 1-6.

Kaur, H. (2015). Two aspects of young children's thinking about different types of dynamic triangles: prototypicality and inclusion. ZDM Mathematics Education, 47(3), 407-420.

Kotsopoulos, D., Cordy, M., \& Langemeyer, M. (2015). Children's understanding of largescale mapping tasks: an analysis of talk, drawings, and gesture. ZDM Mathematics Education, 47(3), 451-463.

Moss, J., Hawes, Z., Naqvi, S., \& Caswell, B. (2015). Adapting Japanese Lesson Study to enhance the teaching and learning of geometry and spatial reasoning in early years classrooms: a case study. ZDM Mathematics Education, 47(3), 371-390.

National Research Council (2006). Learning to think spatially: GIS as a support system in the K-12 curriculum. Washington, DC: National Academy Press.

Ng, O., \& Sinclair, N. (2015). Young children reasoning about symmetry in a dynamic geometry environment. ZDM Mathematics Education, 47(3), 421-434.

Soury-Lavergne, S., \& Maschietto, M. (2015). Articulation of spatial and geometrical knowledge in problem solving with technology at primary school. ZDM Mathematics Education, 47(3), 435-449. 
Timmerman, H., Toll, S., \& Van Luit, J. (2017). The relation between math self-concept, test and math anxiety, achievement motivation and math achievement in 12 to 14-yearsold typically developing adolescents. Psychology, Society \& Education, 9(1), 89-103.

Wai, J., Lubinski, D., \& Benbow, C. P. (2009). Spatial ability for STEM domains: aligning over fifty years of cumulative psychological knowledge solidifies its importance. Journal of Educational Psychology, 101, 817-835. http://www.nap.edu/download.php?record_id=11019. 